\title{
Woman with Partial Androgen Insensitivity Syndrome and Bilateral Sertoli Cell Tumor: A Rare Case Report
}

Dr. Tandra Ghosh ${ }^{1}$, Dr. Shakeela Ishrat ${ }^{2}$, Prof Jasmine Banu ${ }^{3}$, Prof Md Ruhul Amin ${ }^{4}$, Dr. Nighat Sultana ${ }^{5}$, Dr. Sadia Afrin Munmun ${ }^{6}$, Dr. Mumtahena Amir ${ }^{7}$, Dr. Abhijit Roy ${ }^{8}$

${ }^{1}$ Dr. Tandra Ghosh, Resident, Department of Reproductive Endocrinology and Infertility, Bangabandhu Sheikh Mujib Medical University, Shahbag, Dhaka Bangladesh

${ }^{2}$ Dr. Shakeela Ishrat, Associate Professor, Department of Reproductive Endocrinology and Infertility, Bangabandhu Sheikh Mujib Medical University, Shahbag, Dhaka Bangladesh

${ }^{3}$ Prof Jasmine Banu, Professor, Department of Reproductive Endocrinology and Infertility, Bangabandhu Sheikh Mujib Medical University, Shahbag, Dhaka Bangladesh

${ }^{4}$ Prof Md Ruhul Amin, Professor, Department of Pediatric Surgery, Bangabandhu Sheikh Mujib Medical University, Shahbag, Dhaka Bangladesh

${ }^{5}$ Dr. Nighat Sultana, Consultant, Department of Reproductive Endocrinology and Infertility, Bangabandhu Sheikh Mujib Medical University, Shahbag, Dhaka Bangladesh

${ }^{6}$ Dr. Sadia Afrin Munmun, Consultant, Department of Reproductive Endocrinology and Infertility, Bangabandhu Sheikh Mujib Medical University, Shahbag, Dhaka Bangladesh

${ }^{7}$ Dr. Mumtahena Amir, Consultant, Department of Reproductive Endocrinology and Infertility, Bangabandhu Sheikh Mujib Medical University, Shahbag, Dhaka Bangladesh

${ }^{8}$ Dr. Abhijit Roy, Consultant, National Institute of Cardiovascular Disease and Hospital, Dhaka Bangladesh

DOI: $10.36348 /$ sijog.2021.v04i03.005

| Received: 09.02.2021 | Accepted: 20.03.2021 | Published: 30.03.2021

*Corresponding author: Dr. Shakeela Ishrat

\section{Abstract}

Partial Androgen Insensitivity Syndrome (PAIS), a 46XY disorder of sexual differentiation where there is partial loss of function of androgen receptors (AR). The spectrum of clinical presentation can vary in adult from phenotypic female with mild virilization to under virilized male with or without genital ambiguity. Case description: A 25 years old woman presents with primary amenorrhea, ambiguous genitalia and features of mild virilization like hirsutism and voice change. After admission in Reproductive Endocrinology and Infertility Department of Bangabandhu Sheikh Mujib Medical University, she underwent genitoplasty, vestibuloplasty and bilateral gonadectomy. Histopathology of the atrophic testes revealed Sertoli cell tumor. Conclusion: Partial Androgen Insensitivity Syndrome (PAIS) is presented clinically as ambiguous genitalia, as predominant female to male phenotype with varying degree of virilization. Multidisciplinary approach of management aims at appropriate sex assignment, reconstructive surgery, gonadectomy to prevent tumor genesis and hormone replacement therapy.

Keywords: Partial androgen insensitivity syndrome (PAIS), Complete androgen insensitivity syndrome (CAIS), Sertoli cell tumor (SCT), Gonadectomy, Genitoplasty, Vestibuloplasty.

Copyright (C) 2021 The Author(s): This is an open-access article distributed under the terms of the Creative Commons Attribution 4.0 International License (CC BY-NC 4.0) which permits unrestricted use, distribution, and reproduction in any medium for non-commercial use provided the original author and source are credited.

\section{INTRODUCTION}

Partial Androgen Insensitivity Syndrome (PAIS) is a rare condition that results from partial inability of the cell to respond to androgen [1]. It is an $\mathrm{X}$-linked recessive disorder where the partial responsiveness of the cell to androgen hormone impairs the masculinization of male external genitalia as well as development of secondary sexual characteristics at puberty [2]. Clinical presentation may be ambiguous genitalia at birth and in adult a female phenotype with mild virilization or under virilized male who may be fertile or infertile [3]. Management should be done by multidisciplinary approach aiming at appropriate sex assignment, psychological support, removal of cryptorchid testis and management of any detectable tumor, hormone therapy and reconstructive surgery when needed [4]. 


\section{CASE PRESENTATION}

25 years old unmarried lady of lower middleclass family attended the REI (Reproductive Endocrinology and Infertility) Out Patient Department of Bangabandhu Sheikh Mujib Medical University with the complaints of primary amenorrhea, moderate hirsutism, left sided inguinal swelling and clitoromegaly since birth. She was reared as female since childhood. She planned for marriage and wanted reconstruction of external genitalia. There was no positive family history of similar disorders. The patient has normal feminine body habitus with height $155 \mathrm{~cm}$. Breasts are well developed, pubic and axillary hair are normal with moderate hirsutism (Modified FerrimanGallwey Scoring 11). Clitoris was enlarged to about 3.5 $\mathrm{cm}$ in length and $1.5 \mathrm{~cm}$ in width, vagina short and blind, left sided gonad palpable in inguinal region. Urethral orifice is situated in the vaginal canal. Investigations showed total serum testosterone 25.2 $\mathrm{nmol} / \mathrm{L}$ (male range : $8.4-28.8 \mathrm{nmol} / \mathrm{L}$ ), Antimullarian hormone (AMH) $23.5 \mathrm{ng} / \mathrm{ml}$, Follicle stimulating hormone (FSH) 10.26IU/L, uteinizing hormone (LH) 15.79IU/L, Thyroid stimulating hormone (TSH) 3.58 $\mathrm{mIU} / \mathrm{L}$, Prolactin= $12.92 \mathrm{ng} / \mathrm{ml}$. Karyotyping is $46, \mathrm{XY}$, no translocation, inversion or deletion detected. MRI (magnetic resonance imaging) of whole abdomen noted testis like structure in left inguinal region, elongated structure suggestive of deformed testis or lymph node noted at right side of the lower part of pelvic cavity (Fig 1), a slit like structure between bladder and rectum in pelvis (Fig 2). The clinical diagnosis was ambiguous genitalia with perineal hypospadias probably due to Partial Androgen Insensitivity Syndrome.

Bilateral orchidectomy, reduction clitoroplasty and vestibuloplasty were done under general anaesthesia. The surgery was done by a senior pediatric surgeon (RA). Left testis was found in the inguinal canal and right testis in the pelvic cavity retroperitoneally. No rudimentary uterus was present. Abdomen was opened by Pfannenstiel incision. Testes were explored on both side along with spermatic cord and removed. Then abdomen was closed in layers. After that, reduction clitoroplasty with preservation of neurovascular bundle and vestibuloplasty was done by the perineal route. The genital appearance after surgery was female except for the rugosity of overlying skin (Fig 3). The diagnosis was clinical on the basis of clinical presentation, examination and operative findings. Since molecular and genetic studies were not done for financial constraints, the final confirmatory diagnosis could not be done.

Both sided gonads were sent for histopathological examination and report revealed bilateral atrophic testes with Sertoli cell tumor. As there was no feature of malignancy, she was advised hormone replacement therapy with oral conjugated estrogens $625 \mathrm{mcg}$ daily and follows up after 6 months.

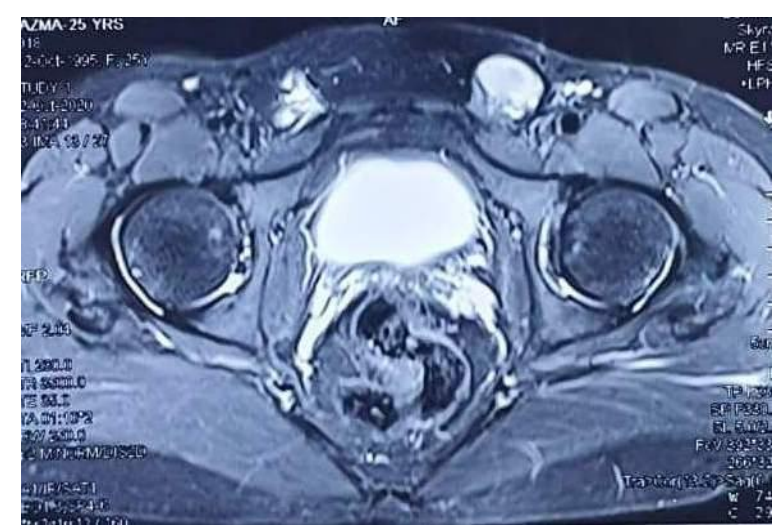

Fig-1: MRI showing the gonads

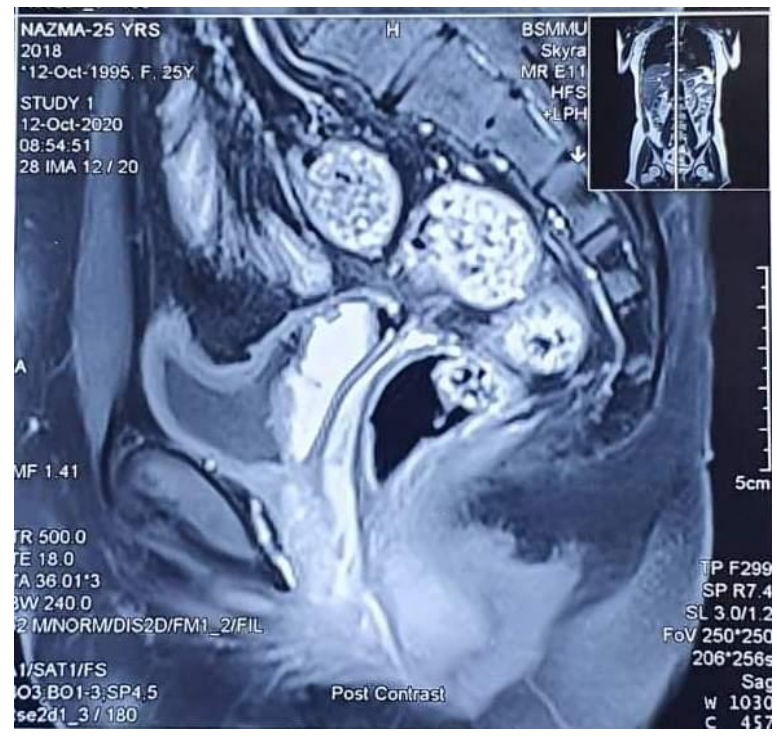

Fig-2: MRI showing absence of uterus 

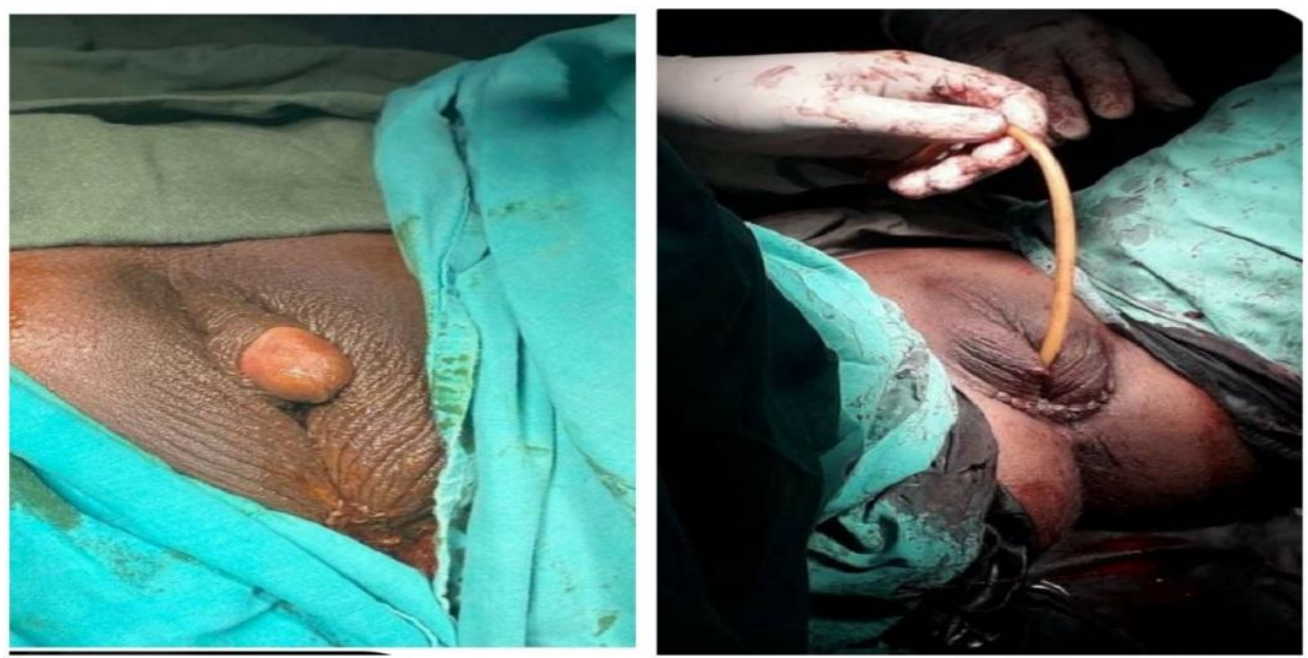

Fig-3: Genital appearance before and after surgery

\section{DISCUSSION}

Androgen Insensitivity Syndrome (AIS), also known as testicular feminization syndrome, is an $\mathrm{X}$ linked recessive disorder where there is mutation in the gene that encodes the androgen receptor (AR). The AR gene is located in the $\mathrm{X}$ chromosome (Xq11-12) [5]. This disorder can produce a variety of phenotype in male having normal testis and testosterone production and absence of any Mullerian structure due to the effect of AMH. The phenotype depends on whether androgen receptors are absent entirely, present but functionally abnormal, or normal but decreased in quality [6-8]. The phenotypic spectrum of AIS is complete AIS (CAIS), partial AIS (PAIS), Reifenstein syndrome and infertile male.

PAIS describes a variety of disorders that result from defect in androgen action less severe than those associated with CAIS. It is also 10 times less common than CAIS [9]. The prevalence of PAIS is approximately 1:20,000 [10]. The spectrum of clinical presentation of PAIS can vary from phenotypic female with mild virilization to under virilized male who may be fertile or infertile. Phenotypic female with mild virilization has normal body hair, external genitalia exhibiting partial fusion of labio-scrotal fold with or without clitoromegaly, underdevelopment of internal genitalia and testes may be undescended within the inguinal canal or abdomen. Breast development, overall body habitus and gender identity are distinctly female. They both virilize and feminize at puberty.

Reifenstein syndrome denotes those having predominantly male phenotype with under virilization (gynecomastia, microphallus, failure of scrotal fusion). Gender identity corresponds with the sex of rearing [11].

Another spectrum of phenotype may present as mildly under masculinized male with infertility [12]. Phenotypic classification is done by Quigley scale (16/7) [2].

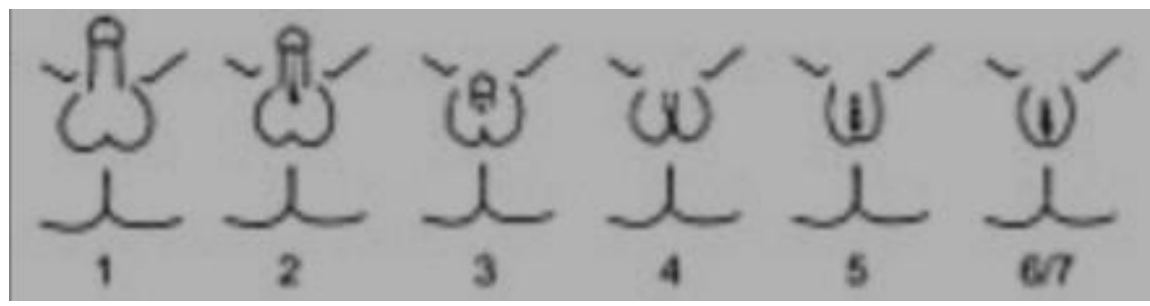

Fig- 4: Schematic representation of Quigley scale

Schematic representation of Quigley scale. Grade 2-5 quantify four degrees of increasingly feminized genitalia that correspond to PAIS. Grade 1 denotes mild AIS and GRADE 6/7 denotes Complete AIS.

Serum testosterone and LH concentration may be normal or elevated. Serum FSH is normal usually. Karyotype is $46 \mathrm{XY}$. Sonography shows absence of any Mullerian structure. MRI is done sometimes to identify ectopic testis and internal genital organ. The most reliable method for diagnosis is to sequence the $A R$ gene using DNA from blood or tissue.

Sex assignment is one of the major tasks that is performed after diagnosis of PAIS. The decision is usually based on the circumstances and input of family, the patient and the medical provider. Genetic counseling is recommended for the patient and the family. 
Tandra Ghosh et al; Sch Int J Obstet Gynec, Mar. 2021; 4(3): 67-71

If the patient is raised as female, estrogen replacement therapy is indicated when gonadectomy is performed after puberty or at the expected time of puberty in case gonadectomy is performed earlier [13]. Genitoplasty also may be done if needed.

If the patient is reared as male, then testosterone or DHT can be given for penile growth. Surgery to repair male sex organ and mastectomy for gynecomastia can also be done if needed. Gonadectomy is done for cryptorchid testis to prevent development of malignancy.

Manuel et al. reported that the risk of malignancy increases with age. Risk is $3.6 \%$ and $33 \%$ in patients of 25 and 50 years of age respectively [14]. Seminoma and gonadoblastoma are most common malignancy in this syndrome but benign forms such as adenoma, Leydig cell and/or Sertoli cell tumor are other possibilities [15-17].

The majority of Sertoli cell tumors are benign, malignancy is very rare accounting for approximately $1 \%$ of all testicular carcinoma. Orchidectomy is the treatment of choice. Retroperitoneal lymph node dissection can be done in malignant case. No other therapy is recommended because they poorly respond to chemotherapy or radiotherapy [18].

\section{CONCLUSION}

PAIS is a rare variety of XY DSD (Disorder of Sexual Development) which is 10 times less common than CAIS. It is an X-linked recessive disorder which results from mutation in AR gene producing inability of the cell to respond to androgen. It may be presented clinically in infant as ambiguous genitalia and in adult as predominant female to male phenotype according to varying degree of virilization. Management should be done by multidisciplinary approach aiming at appropriate sex assignment, reconstructive surgery if required, psychological support to the patient and the family, gonadectomy to prevent tumor genesis followed by hormone replacement therapy.

\section{REFERENCES}

1. Galani, A., Kitsiou-Tzeli, S., Sofokleous, C., Kanavakis, E., \& Kalpini-Mavrou, A. (2008). Androgen insensitivity syndrome: clinical features and molecular defects. Hormones, 7(3), 217-229.

2. Quigley, C. A., De Bellis, A., Marschke, K. B., ElAwady, M. K., Wilson, E. M., \& French, F. S. (1995). Androgen receptor defects: historical, clinical, and molecular perspectives. Endocrine reviews, 16(3), 271-321.

3. Gardó, S., \& Papp, Z. (1974). Clinical variations of testicular intersexuality in a family. Journal of medical genetics, 11(3), 267-270.
4. Taylor, H. S., Pal, L., \& Sell, E. (2019). Speroff's clinical gynecologic endocrinology and infertility. Lippincott Williams \& Wilkins.

5. Brown, C. J., Goss, S. J., Lubahn, D. B., Joseph, D. R., Wilson, E. M., French, F. S., \& Willard, H. F. (1989). Androgen receptor locus on the human X chromosome: regional localization to Xq11-12 and description of a DNA polymorphism. American journal of human genetics, 44(2), 264.

6. Griffin, J. E., Punyashthiti, K., \& Wilson, J. D. (1976). Dihydrotestosterone binding by cultured human fibroblasts. Comparison of cells from control subjects and from patients with hereditary male pseudohermaphroditism due to androgen resistance. The Journal of clinical investigation, 57(5), 1342-1351.

7. Kaufman, M., Straisfeld, C. I. P. I. A., \& Pinsky, L. (1976). Male pseudohermaphroditism presumably due to target organ unresponsiveness to androgens. Deficient 5alpha-dihydrotestosterone binding in cultured skin fibroblasts. The Journal of clinical investigation, 58(2), 345-350.

8. Griffin, J. E. (1979). Testicular feminization associated with a thermolabile androgen receptor in cultured human fibroblasts. The Journal of clinical investigation, 64(6), 1624-1631.

9. Griffin, J. E. (1992). Androgen resistance-the clinical and molecular spectrum. New England Journal of Medicine, 326(9), 611-618.

10. Brinkmann A.O. (2001). Molecular basis of androgen insensitivity. Molecular and Cellular Endocrinology, 179(1-2), 105-109.

11. Wilson, J. D., Harrod, M. J., Goldstein, J. L., Hemsell, D. L., \& MacDonald, P. C. (1974). Familial incomplete male pseudohermaphroditism, type 1: evidence for androgen resistance and variable clinical manifestations in a family with the Reifenstein syndrome. New England Journal of Medicine, 290(20), 1097-1103.

12. Aiman, J., Griffin, J. E., Gazak, J. M., Wilson, J. D., \& MacDonald, P. C. (1979). Androgen insensitivity as a cause of infertility in otherwise normal men. New England Journal of Medicine, 300(5), 223-227.

13. Illig, R., DeCampo, C., Lang-Muritano, M. R., Prader, A., Torresani, T., Werder, E. A., \& Schenkel, L. (1990). A physiological mode of puberty induction in hypogonadal girls by low dose transdermal 17 $\beta$-oestradiol. European journal of pediatrics, 150(2), 86-91.

14. Manuel, M., Katayama, K. P., \& Jones Jr, H. W. (1976). The age of occurrence of gonadal tumors in intersex patients with a Y chromosome. American journal of obstetrics and gynecology, 124(3), 293300 .

15. Kravarusic, D., Seguier-Lipszyc, E., Feigin, E., Nimri, R., Nagelberg, N., \& Freud, E. (2011). Androgen insensitivity syndrome: risk of malignancy and timing of surgery in a paediatric 
and adolescent population. African Journal of Paediatric Surgery, 8(2), 194.

16. Gurer, I. E., Demirkiran, A. E., \& Sare, M. (2000). Sertoli Cell Tumor in Two Sibs with Testicular Ferminization Syndrome. Turkish Journal of Medical Sciences, 30(4), 385-388.

17. García, G., \& Bolufer, E. (2010). Sertoli cell tumor, a rare testicular tumor, our experience and review of the literature. Archivos espanoles de urologia, 63(5), 392-395.

18. Kravtsov, O., \& Mesa, H. Sertoli cell tumor, NOS. Pathology Outlines.com website. https://www.pathologyoutlines.com/topic/testisSert oliNOS.html. 